Genevieve Milliken

Professor Smith-Cruz

Pratt Institute School of Information

INF0 652: Reference and Instruction

17 November 2018

\title{
Reference Services to Incarcerated Individuals
}

Prisons have not been particularly innovative in finding ways for the incarcerated to access and receive information. Modern informational outlets (such as full-service libraries and search platforms) and basic technologies (including computers, mobile devices, and the internet) routinely are excluded from most penal facilities. Normally, there is some basic television, radio, and regulated phone calls, often paid for by families and loved ones. At some lower-security facilities, there may be limited access to email. These strictures on access are often implemented in the name of prison security and a concern about contraband, which have contributed to a deep level of information paucity in jails and prisons. The focus on suppression in the service of security has resulted in institutional approaches that appear to be unable to entertain the possibility of other less restrictive options. As a result, those incarcerated often find themselves in an information-impoverished space that sees access to most forms of knowledge as a source of danger and disruption rather than a route to education, correction, and rehabilitation.

To be clear, when I note the informational paucity of carceral environments, I advisedly section off modes of intra-prison communication (i.e. incarcerated individual-to-incarcerated individual). While intra-prison communication and exchange is as an important and autonomous form of information gathering and consumption (Drabinski and Rabina, 2015), I am primarily concerned here with conditions of the current penal system as they impact an individual's access to wider realms of information. Specifically, this includes: (1) the ponderous means by which an incarcerated individual can have access to information on the "outside" and (2) the ways in which outside information is intermediated by others and does not always reflect the incarcerated 
individual's desired outcomes. First, access to "outside" information in prisons is limited by, and heavily reliant on, what can be viewed as outmoded means. The incarcerated submit handwritten reference requests (or even FOIL and FOIA requests) to prison personnel or librarians or to libraries (via snail mail) with corrections services. Second, any information requested is contingent on the intermediation of those also residing on the "outside"-i.e. social workers, librarians, library graduate students, volunteers, and other agencies-who must conform to limits placed by the jail or prison and also function within certain constraints related to those providing the information. These strictures include factors such as available research time, funding, access, effort, and the availability (or even existence) of requested information. Indeed, the first restriction (outmoded request methods) falls under the control of the jails and prisons. However, the second form-intermediation, or the act of bridging-is something that affects information professionals as they interpret, collect, and curate responses to prison reference questions.

\section{Intermediation}

As (budding) library professionals, and as concerned citizens working toward greater social justice, there is a lot that can be done to meet the basic informational needs of those currently in the carceral system. In New York City, where there is both an activist community and a high percentage of incarcerated individuals, there are many avenues for championing an incarcerated person's right to access. Working within (and perhaps in spite of) current restrictions dictated by the penal system, individuals can partner with existing organizations to lend a hand. These organizations include: NYC Books Through Bars, NYPL's Correctional Services, BPL's Jail and Prison Libraries, and the Prison Library Support Network. As a Pratt student, and as a concerned citizen with formerly incarcerated family members, my volunteership and graduate training has led me to become familiar with answering reference letters from incarcerated individuals. The process of fulfilling such requests, however, ironically places me, and others like me, in a somewhat precarious situation. As LIS professionals, we are trained to find ways to provide access to anyone seeking information and usually do so through an evolving conversation or reference 
interview. Rather than mediate information, we work to facilitate the seeker and help that person find information according to her or his needs and wants. When filling reference requests from the incarcerated, there is no conversation-there is only a message that requires interpretation. In turn, we cease being facilitators and become mediators who make choices regarding length, content, sufficiency, etc. without any further input from the person asking. These choices can be, and often are, confounding, bordering on agonizing. Of course, that type of emotional response is likely a good thing as it serves as a persistent reminder to curate information mindfully, answer questions thoroughly, and to be respectful in the overall response.

\section{Answering Letters}

As was the case with my classmates, I had to make various decisions and determinations regarding the right path forward when answering my three reference letters over the course of the semester. Even when face-to-face with an information seeker, reference questions can often be vague or difficult to answer. This is especially so when attempting to meet a reference request for someone only through a letter and with no real mechanism for feedback. For instance, my first letter of the semester came from an incarcerated individual whose grandfather had recently had a stroke. This person requested information on strokes-what causes them, what physical rehabilitation options are available, and what drugs are currently in trials. This request required multiple decisions: at what level (educational and linguistic) should I provide information? How much should come from sources directed toward general audiences? How much should come from medical journals and from scientific studies? How much jargon would be too much? At what point would or could the information provided become overwhelming? It also raised various conundrums. How might the information accidentally veer toward being medical advice? How might my own lack of knowledge on the subject introduce biases or blind spots that might do the information seeker a disservice? My efforts to balance these questions and pitfalls led me to

compile a letter with a range of information. Some of what was offered was likely beyond the ability of a layperson to understand. On the whole, however, I felt that I provided 
information that the information seeker could share with her or his family and start a conversation with medical professionals.

The second letter was a bit less fraught, and allowed me to be of service in a more creative way. The request sought information about the flora and fauna of the Florida Everglades. It also included a request, if there was space left over but still within the page limit of the response, for information on healthy protein eating habits for for adults over 40 . For this letter, I researched the Everglades in terms of: history, ecology, plants, animals, and conservation efforts. I wove together text and images-contemporary and historical-derived from governmental and non-profit sources. The subject matter lent itself to being organized in a roughly narrative manner that took the reader on a virtual tour through the Everglades. As the request also contained a second subject, I carefully balanced my response so that I could include information about eating habits. For this portion of the letter, I included information from governmental nutrition sites as well as general interest sources that discussed approaches to good nutrition for adults over 40 .

The third letter allowed me to foreground the possibilities of world travel after incarceration. In this case, the inquiry involved questions about passport restrictions for those with felony convictions. To answer this request, I researched governmental sites and provided the pertinent State Department regulations on the topic. From this research came key information about formerly incarcerated people and travel. First, once a person's sentence is over, she or he may travel freely assuming that she or he is not on probation or parole and has a valid passport. This can be complicated by the fact that the United States will deny, or revoke, passports for those convicted of certain drug trafficking charges. Without a valid passport, a person cannot legally exit one country or enter another-even if she or he is no longer on probation or parole. Second, a felony conviction can prevent a person from entering countries with strict visa provisions even with a valid passport. For example, Canada may deny (and has denied) visas to people convicted of drunk driving. I next turned to various sites dedicated to traveling with a passport, but not necessarily with 
a visa. It turns out that are many options, including those under the Schengen agreement (i.e. the Eurozone countries) that only require a valid passport. Multiple Latin American and Caribbean countries also fall under this category. I then took the opportunity to suggest several potential sites and included pictures and descriptions of them for the requester to consider.

Even though these letters were rewarding for me to prepare, and even if my efforts were greatly appreciated, it did not keep me from reflecting on all the collateral effects that accompany incarceration. I was struck by how a seemingly concerned family member could not care for a loved one who just had a stroke, or a nature enthusiast could not (at least at the movement) take a trip down to Florida to visit the Everglades, or that travel for a formerly incarcerated individual would automatically be viewed as restrictive, regardless of the fact that citizenship (i.e. what is needed for a passport) and having a criminal record are largely mutually exclusive. Most importantly, I was struck by the way that incarceration alters how information is accessed and transmitted. For both the information seeker and the librarian (or library student) put into the role of mediator, the effects of a system focused on restriction rather than correction or rehabilitation are chilling. The normal give-and-take of the reference interview is reduced to a unidirectional mode of communication that drains it of its immediacy, depth, and texture.

\section{Not a Foregone Conclusion: LIS and Social Justice}

Answering a few prison reference letters for a few hours over the course of the semester is, in and of itself, a modest and imperfect act. Yet, talking about the process is a conversation that needs to be situated within the larger discourse of LIS and its connection to social justice. Some themes under the umbrella of social justice (i.e. discourses on power, privilege, whiteness, etc.) have been touched upon in INFO 652: Reference and Instruction. In LIS curricula, paying attention to sources and voices (especially those scholars, subjects, and frameworks not conforming to the traditional notions of librarianship), we encounter LIS narratives working to shed light on ethical concerns and, in answering prison reference 
letters, we are participating in social justice librarianship. Through these discussions comes the promise of building socially responsible librarians and information specialists as well as the creation of humane, culturally competent professionals who can meet the needs of diverse and deserving patrons, including those incarcerated.

\section{Sources}

Drabinski, E., \& Rabina D. (2015). Reference services to incarcerated people, Part I: Themes emerging from answering inmates' reference questions. Reference and User Services Quarterly [RUSQ] 55:1, 42-48.

Drabinski, \& E., Rabina D. (2015). Reference services to incarcerated people, Part II: Sources and learning outcomes. Reference and User Services Quarterly [RUSQ] 55:2, 123-131. 